\title{
Erratum to: Arthroscopic reconstruction of the popliteus complex: accuracy and reproducibility of a new surgical technique
}

\author{
Karl-Heinz Frosch ${ }^{1,2} \cdot$ Ralph Akoto $^{2} \cdot$ Maximilian Heitmann $^{1,2}$ • \\ Elena Enderle $^{1} \cdot$ Antonios Giannakos $^{2} \cdot$ Achim Preiss $^{1,2}$
}

Published online: 14 April 2015

(C) European Society of Sports Traumatology, Knee Surgery, Arthroscopy (ESSKA) 2015

\section{Erratum to: Knee Surg Sports Traumatol Arthrosc \\ DOI 10.1007/s00167-014-3000-y}

Unfortunately, the given and family name of the co-author, Maximilian Heitmann, was incorrectly published in the original publication. The correct name should read as Maximilian Heitmann, respectively. The original article has been updated accordingly.

The online version of the original article can be found under doi:10.1007/s00167-014-3000-y.

Karl-Heinz Frosch

k.frosch@asklepios.com

1 Department of Trauma and Reconstructive Surgery, Asklepios Clinic St. Georg, Lohmühlenstr. 5, 20099 Hamburg, Germany

2 Department of Knee and Shoulder Surgery, Sports Traumatology, Asklepios Clinic St. Georg, Hamburg, Germany 